\title{
BURDEN IN THE CAREGIVERS OF TRAUMATIC SPINAL CORD INJURED
}

\author{
R. Sharadha Naveen ${ }^{1}$
}

${ }^{1}$ Assistant Professor, Department of Psychiatry, Dr. B. R. Ambedkar Medical College Hospital, Bangalore.

\section{ABSTRACT}

\section{BACKGROUND}

There are very few events which affect a person's entire lifestyle as profoundly as a spinal cord injury (SCI) and more so the traumatic injuries. The victims in their young and productive years face multiple medical, social and vocational complications. This causes burden and suffering not only to the victim but also to their families, the health care system and the community. Despite this, a comprehensive rehabilitation program including assessment of caregiver burden can often enable these individuals to function adequately.

Objectives

1. To assess the burden in caregivers of traumatic spinal cord injured patients.

2. To correlate caregiver burden with patient's disability, handicap status and quality of life.

\section{MATERIALS AND METHODS}

A cross-sectional observational study was carried out on 50 primary caregivers of SCI patients one year post injury. Caregivers were assessed with Zarit Burden Inventory (ZBI) after screening with General Health Questionnaire (GHQ-28).

\section{RESULTS}

Two-thirds of caregivers were aged below 40 years. Majority of them (62\%) were females. Three-fourths of caregivers perceived higher scores of burden. Significant correlations noted between patient's functional outcomes and ZBI scores.

\section{CONCLUSION}

This study shows that caregiver burden is an important factor to be considered as a part of every rehabilitation effort for traumatic SCI patients. Assessment of burden would guide medical professionals to prevent burnout of caregivers and help them to provide long-term care for their patients.

\section{KEYWORDS}

Traumatic SCI; Caregiver Burden; ZBI.

HOW TO CITE THIS ARTICLE: Naveen RS. Burden in the caregivers of traumatic spinal cord injured. J. Evolution Med. Dent. Sci. 2016;5(100):7310-7313, DOI: 10.14260/jemds/2016/1655

\section{BACKGROUND}

Though numerous pathologies such as infection, tumour, demyelination and vascular compromise have been noted to cause spinal cord injury, trauma exceeds the whole group in causing spinal cord injury. In its consequences, a spinal cord injury (SCI) is like a ripple caused by a stone thrown in a pond, involving increasingly wider areas of the lives of the persons involved and those around them also being affected. Over the past 50 years, improved knowledge in physical medicine and rehabilitation and setting up of centres specialising in SCI patients have allowed a significant increase in life expectancy among them, with a large number of patients going back home. ${ }^{1}$

Spinal cord injury leads to severe functional loss and disability. SCI has an immediate and longterm impact on all areas of these individual's physical and psychosocial functioning. Multiple medical, social and vocational

Financial or Other, Competing Interest: None.

Submission 23-11-2016, Peer Review 02-12-2016,

Acceptance 08-12-2016, Published 15-12-2016.

Corresponding Author:

Dr. R. Sharadha Naveen,

\#264, Lakshmi Nilaya, $6^{\text {th }} C$ Main

HMT Layout, V. V. Nagar,

RT Nagar Post, Bangalore-560032.

E-mail:drrsharadhan@yahoo.com

DOI: $10.14260 /$ jemds/2016/1655 complications affect the victims who are young and in their productive stages of life. This causes burden and suffering not only to the victim but also to their families, to the health care system and to the community. The human and financial costs and implications of SCI are enormous. Despite the devastating physical, social and emotional consequences of SCI, a comprehensive rehabilitation program can often enable these individuals to function comfortably, independently, and productively at home as well as in the work place. Caregiver burden refers to the physical, psychological, social and financial impact of caring for another person who is ill, disabled or otherwise functionally impaired. Often the term is used in reference to informal caregivers i.e., person acting in an unpaid, non-professional capacity such as family members. ${ }^{2}$ To a great extent now, family members are responsible for a wide range of services provided formally by traditional health care providers. ${ }^{3}$

There is extremely limited information about the impact of caregiving post SCI injury. Literature search did not reveal any studies from India regarding the assessment of caregiver burden in relatives of patients with SCI as such. The current study has been a primary effort in this direction. During initial rehabilitation, the major focus is on the patient. Caregivers are the forgotten half of the rehabilitation process. However, we are well aware that caregivers bear an important, oftensubstantial amount of burden on them. The underlying assumption is that not only a study of this process important in its own right, but the well-being of the caregiver is likely 
directly tied to the well-being of individuals with spinal cord injury.

Results from a caregiver burden assessment would provide empirical evidence that can be utilised in the development of evaluation of beneficial services and programs for caregivers. In terms of SCI individuals, this may identify adequate resources and prevent institutionalisation and abandonment.

\section{Aims and Objectives}

1. To assess the burden in caregivers of traumatic spinal cord injured patients.

2. To correlate caregiver burden with patient's disability, handicap status and quality of life.

\section{MATERIALS AND METHODS}

The present study was of cross-sectional and observational nature. This was conducted on the caregivers of individuals with Spinal Cord Injury (SCI), visiting the Department of PMR (Physical Medicine and Rehabilitation) along with the patients in a tertiary care hospital, Bangalore. First, records of patients with traumatic injuries of spinal cord, with minimum one year post injury who had enrolled for a research project assessing their functional outcomes i.e., impairment, disability, handicap and quality of life and correlation between them if any were identified. ${ }^{4}$ Caregivers of above patients were consulted for potential participants.

\section{Inclusion Criteria}

1. Primary caregivers of SCI patients (Living with the patient in the community).

2. Aged between 15 to 55 years.

\section{Exclusion Criteria}

1. Caregivers with major psychiatric illness as detected on General Health Questionnaire - 28 (GHQ-28).

2. Comorbid physical or cognitive problems.

Those who met the above criteria were contacted and the nature of the study was explained. Informed consent was taken from the caregiver. Ethical committee clearance was obtained. Information about socio-demographic characteristics of the caregivers-age, gender, occupation, education and relationship with the patient were collected.

All together 50 caregivers were interviewed during the study period of one year. Caregivers were screened with GHQ28. 5 Those who scored a cut-off of 9 and above were excluded and their caregiving burden was assessed by ZBI (Zaritburden inventory). ${ }^{6}$

In the primary study of Quality of life of traumatic spinal cord injured by the author, the functional outcomes of SCI were evaluated through ICF conceptual framework ${ }^{7}$ (International Classification of Functioning, Disability and Health). Standardised measures were used to assess impairment (ASIA impairment scale), ${ }^{8}$ disability (Functional Independence Measure-FIM), ${ }^{9}$ handicap (Craig's Handicap Assessment and Reporting Technique-CHART) ${ }^{10}$ and quality of life (WHOQOL-BREF11). The burden scores obtained were correlated with above said parameters of SCI patients.

\section{Scales Used}

1. Zarit Burden inventory (ZBI).

2. General Health Questionnaire-28 (GHQ-28).

\section{Zarit Burden Inventory (ZBI)}

The Zarit Burden interview is used extensively in caregiver research. Originally published in 1980 as 29 -item scale, ZBI was revised and resulting 22-item scale is commonly used today.6,11 The ZBI measures subjective distress and perceptions of social, physical, financial and emotional burden among caregivers. Items are rated on a 5-point scale and scores are added for the 22 questions. The total score ranges from 0-88. A higher score correlates with higher burden.

The ZBI has been consistently shown to have excellent internal consistency with a Cronbach's alpha range between 0.85 and 0.93 in studies by Hebert et al, Matsuda 1999, Arai et al.12,13,14 Reliability for different translations of the scale have also shown good internal consistency. Scores on the ZBI have also been significantly correlated with the care recipients' functional ability or behavioural problems. ${ }^{12}$

\section{General Health Questionnaire- 28 (GHQ-28)}

Goldberg and Hiller in 1979 developed a scaled version of GHQ on the basis of the result of principal component analysis. ${ }^{5}$ Since then, the GHQ-28 version is used extensively in community-based studies and has gained popularity. GHQ was designed in order to identify psychiatric morbidity in general practice. It takes about 20-30 min. to administer. The questionnaire provides information about the recent mental status (1 month), to identify the presence of possible psychiatric disturbance.

The reliability and validity of the questionnaire are established by several authors (Sriram et al). The test-retest reliability is 0.76 , validity is 0.80 , sensitivity is $95.7 \%$ and specificity is $87.8 \%$. GHQ has fairly good discriminating efficiency in terms of distinction between normal and ill persons, but it is less efficient in discriminating various degrees of psychiatric illness. Here in this study, a cut-off of 9 and above is considered to screen caregivers.

\section{Statistics}

Mean and standard deviation were used to describe continuous variables and frequency distributions were obtained for categorical data. Pearson's correlation coefficients were determined for associations between FIM score for disability, CHART score for handicap, quality of life scores and the study parameter of caregiver burden by ZBI scores.

\section{RESULTS}

Two-thirds of caregivers were aged below 40 years. Majority of them (62\%) were females. $82 \%$ were educated only up to high school. Mothers and wives contributed for $56 \%$ of the group. Caregiver burden as assessed on Zarit Burden Inventory showed significant negative correlation with occupational domain of CHART and physical, psychological and environmental domains of QOL of a SCI patient. The caregiver burden also correlated moderately with disability, physical independence, mobility and social integration domains of CHART in an inverse relationship as shown in tables 5, 6 and 7 . 


\begin{tabular}{|c|c|c|}
\hline Age in Years & Number & \% \\
\hline Up to 20 & 5 & 10.0 \\
\hline $21-30$ & 9 & 18.0 \\
\hline $31-40$ & 18 & 36.0 \\
\hline $41-50$ & 14 & 28.0 \\
\hline $51-60$ & 4 & 8.0 \\
\hline Total & 50 & 100.0 \\
\hline Mean \pm SD & \multicolumn{2}{|c|}{$36.94 \pm 10.59$} \\
\hline Table 1. Age Distribution of Caregivers
\end{tabular}

\begin{tabular}{|c|c|c|}
\hline Sex & Number & $\mathbf{\%}$ \\
\hline Male & 19 & 38.0 \\
\hline Female & 31 & 62.0 \\
\hline Total & $\mathbf{5 0}$ & $\mathbf{1 0 0 . 0}$ \\
\hline \multicolumn{2}{|c|}{ Table 2. Sex Distribution of Caregivers Studied } \\
\hline
\end{tabular}

\begin{tabular}{|c|c|c|}
\hline Caregivers Studied & Number & $\mathbf{\%}$ \\
\hline Illiterate & 15 & 30.0 \\
\hline Up to High School & 26 & 52.0 \\
\hline PUC & 4 & 8.0 \\
\hline Degree \& Above & 5 & 10.0 \\
\hline Total & $\mathbf{5 0}$ & $\mathbf{1 0 0 . 0}$ \\
\hline Table 3. Educational Levels of Caregivers Studied
\end{tabular}

Table 3. Educational Levels of Caregivers Studied

\begin{tabular}{|c|c|c|}
\hline Relationship & Number & \% \\
\hline Father & 5 & 10.0 \\
\hline Mother & 7 & 14.0 \\
\hline Wife & 21 & 42.0 \\
\hline Husband & 2 & 4.0 \\
\hline Brother & 5 & 10.0 \\
\hline Sister & 1 & 2.0 \\
\hline Son & 2 & 4.0 \\
\hline Daughter & 1 & 2.0 \\
\hline Cousin/Nephew & 4 & 8.0 \\
\hline Uncle/Aunt & 2 & 4.0 \\
\hline Total & $\mathbf{5 0}$ & $\mathbf{1 0 0 . 0}$ \\
\hline Table 4. Relationship of Caregivers with the Patients \\
\hline \multicolumn{2}{|c}{}
\end{tabular}

\begin{tabular}{|c|c|c|}
\hline Grade & Number & $\mathbf{\%}$ \\
\hline $0-20$ & 8 & 16 \\
\hline $21-40$ & 20 & 40 \\
\hline $40-60$ & 19 & 38 \\
\hline$>60$ & 3 & 6 \\
\hline Total & $\mathbf{5 0}$ & $\mathbf{1 0 0}$ \\
\hline \multicolumn{3}{|c|}{ Table 5. ZBI Score } \\
\hline
\end{tabular}

\begin{tabular}{|c|c|c|}
\hline \multirow{2}{*}{ Parameters } & \multicolumn{2}{|c|}{ FIM Score } \\
\cline { 2 - 3 } & r-value & p-value \\
\hline ZBI Score & -0.331 & $0.019^{*}$ \\
\hline \multicolumn{2}{|c|}{ Table 6. Correlation of ZBI with FIM scores } \\
\hline
\end{tabular}

\begin{tabular}{|c|c|c|}
\hline \multirow{2}{*}{ Chart Scores } & \multicolumn{2}{|c|}{ Zarit Burden Scores } \\
\cline { 2 - 3 } & r-value & p-value \\
\hline Physical Independence & -0.343 & $0.015^{*}$ \\
\hline Cognitive Independence & -0.167 & 0.246 \\
\hline Mobility & -0.279 & $0.050^{*}$ \\
\hline Occupation & -0.542 & $0.001^{* *}$ \\
\hline Social Integration & -0.339 & $0.016^{*}$ \\
\hline $\begin{array}{c}\text { Economic } \\
\text { Self-Sufficiency }\end{array}$ & -0.125 & 0.386 \\
\hline \multicolumn{2}{|c|}{ Table 7. Correlation of ZBI with Chart Scores } \\
\hline
\end{tabular}

\begin{tabular}{|c|c|c|}
\hline & \multicolumn{2}{|c|}{ ZBI Score } \\
\hline QOL Scores & r-value & p-value \\
\hline Physical Domain & -0.440 & $0.001^{* *}$ \\
\hline $\begin{array}{c}\text { Psychological } \\
\text { Domain }\end{array}$ & -0.568 & $<0.001^{* *}$ \\
\hline $\begin{array}{c}\text { Environmental } \\
\text { Domain }\end{array}$ & -0.446 & $<0.001^{* *}$ \\
\hline $\begin{array}{c}\text { Social Relationship } \\
\text { Domain }\end{array}$ & -0.232 & 0.105 \\
\hline \multicolumn{2}{|c|}{ Table 8. Correlation of ZBI with QOL Scores } \\
\hline
\end{tabular}

\section{DISCUSSION}

After an individual becomes spinal cord injured, there is often the need for assistance in one's daily activities. This can range from help with bathing and dressing to doing one's bowel program or providing transportation. The health and wellbeing of the SCI caregiver is very important, as this can affect the well-being of the individuals with SCI.

The assessment of caregiver's subjective burden is defined as the extent to which Caregivers perceived their emotional/physical health, social life and financial status to have changed as a result of caring for their relative with SCI. This will help clinicians to investigate the factors affecting the level of stress and design appropriate intervention strategies.

The caregiver burden was assessed using Zarit burden inventory (ZBI), the most frequently used and validated questionnaire in this population. In the present study, fifty caregivers of SCI patients were assessed for caregiver burden and the scores showed significant correlation with patient's quality of life.

Timothy Elliot et al in 1998 found that caregivers experiencing high levels of distress and burden impact the patient's QOL. ${ }^{3}$ Primary caregivers of people with SCI showed significantly lower QOL than people who were not caregivers, but no relationships with impairment parameters could be demonstrated in a study by Unalan et al. 15

Marcel Post et al report that burden is higher with older and female caregivers and caregivers of persons with more disability experience heavy burden. ${ }^{16}$

The well-being of persons with SCI has been demonstrated to be related to adequate social support. Susan Mockus (1998) found that younger the patient, higher the level of burden perceived by caregiver. ${ }^{17}$ Faison et al reported that caregivers experiencing high levels of burden negatively impact patient's QOL.18 The caregiver burden shows significant correlation with patients disability in the current study.

No review has been found in relation to handicap of SCI patient and caregiver burden. In this study, the ZBI score correlated with occupational domain ( $\mathrm{p}$-value $<0.001$-strongly significant) and physical independence, mobility and social integration domains ( $p$-value $<0.05$-moderately significant) of Chart.

Chan et al reported that partners of persons with SCI perceived more distress than patients themselves. ${ }^{19}$

\section{CONCLUSIONS}

This is a cross-sectional study carried out on fifty primary caregivers of traumatic SCI patients visiting the PMR department of a tertiary healthcare centre. $64 \%$ caregivers were in the age group 30-50 years and $82 \%$ of the total caregiver population were poorly educated. $62 \%$ were females; $42 \%$ were spouses and $14 \%$ were mothers. The 
caregiver burden correlated significantly with all the domains of patient's QOL. ZBI scores correlated significantly with occupation, physical independence, mobility and social integration domains of handicap and also with disability. The results show the need for the assessment of caregiver's health for a comprehensive rehabilitation effort in SCI patients. Better care of caregivers will ensure their continued participation in the welfare of traumatic SCI patients.

\section{Limitations}

The study was confined to caregivers of patients who came for follow-up post one or more years of spinal injury. Patient variables like secondary complications, medical and surgical interventions and previous rehabilitation efforts were not considered. Duration of caregiving may also confound the perception of felt burden.

The caregiver burden was correlated only with patient's disability, handicap and QOL as a part of main assessment of quality of life in traumatically spinal cord injured and many sociodemographic factors were not considered.

\section{Acknowledgements}

The author would like to thank Dr. M. Prakash Appaya, Retd. Professor of Psychiatry and Dr. Kurian Zachariah, Professor and HOD, Department of Physical Medicine and Rehabilitation, St. Johns Medical College Hospital, Hosur Road, Bangalore for their valuable guidance.

\section{REFERENCES}

1. Guttman L. Spinal cord injuries: comprehensive management and research, $2^{\text {nd }}$ edn. Oxford: Blackwell scientific publications 1976.

2. Caregivers for SCI. Spinal cord injury-InfoSheet\#17. Rehabilitation research and training centre in secondary complications in spinal cord injury. University of Alabama/Birmingham, department off physical medicine and rehabilitation 1998. http://www.spinalcord.uab.edu.

3. Elliot TR, Shewchuk RM. Recognizing the family caregiver: Integral and formal members of the rehabilitation process. Journal of Vocational Rehabilitation 1998;10(2):123-7.

4. Naveen SR. Quality of life in traumatic spinal cord injured. J Evid Based Med Healthc 2016;3(5):176-83.

5. Goldberg DP, Williams P. A User's guide to the general health questionnaire. Windsor, Berks: NFER-Nelson 1988.

6. Zarit SH, Reever KE, Bach-Peterson J. Relatives of the impaired elderly: correlates of feelings of burden. Gerontologist 1980;20(6):649-55.
7. Jette AM. Physical disablement concepts of physical therapy research and practice. Phys Ther 1994;74(5):380-6.

8. Ditunno JF, Young W, Donovan WH, et al. The international standard booklet for neurological and functional classification of spinal cord injury. Paraplegia 1994;32(2):70-80.

9. Dodds TA, Martin DP, Stolov WC, et al. A validation of the functional independence measurement and its performance among rehabilitation in patients. Arch Phys Med Rehabil 1993;74(5):531-6.

10. Whiteneck GG, Charlifue SW, Gerhart KA, et al. Quantifying handicap: a new measure of long term rehabilitation outcomes. Arch Phys Med Rehabil 1992;73(6):519-26.

11. The WHOQOL group. Development of the World Health Organization WHOQOL-BREF quality of life assessment. Psychological Medicine 1998;28(3):551-8.

12. Hebert R, Bravo G, Preville M. Reliability, validity and reference values of zarit burden interview for assessing informal caregivers of community dwelling older persons with dementia. Canadian Journal on Aging 2000;19(4):494-507.

13. Matsuda 0 . Reliability and validity of the subjective burden scale in family caregivers of elderly relatives with dementia. International Psychogeriatrics 1999;11(2):159-70.

14. Arai $Y$, Washio M. Burden felt by family caring for the elderly members needing care in southern Japan. Aging and Mental Health 1999;3(2):158-64.

15. Unalan H, Gençosmanoğlu B, Akgün K, et al. Quality of life of primary caregivers of spinal cord injury survivors living in the community: controlled study with short form-36 questionnaire. Spinal Cord 2001;39:318-22.

16. Post MW, Bloemen J, de Witte LP. Burden of support for partners of persons with spinal cord injuries. Spinal Cord 2005;43(5):311-9.

17. Parks SM, Novielli KD. A practical guide to caring for caregivers. American Family Physician 2000; 62(12): 2613-2620.

18. Faison KJ, Faria SH, Fran D. Caregivers of chronic ill elderly: perceived burden. Journal of Community Health Nursing 1999;16(4):243-53.

19. Chan RC, Lee PW, Lieh-Mak F. Coping with spinal cord injury: personal and marital adjustment in the Hong Kong Chinese setting. Spinal Cord 2000;38(11):687-96. 